\title{
Dietary Diversity and Associated Factors Among Infants and Young Children in Wolaita Zone, Southern Ethiopia
}

\author{
Getu Gamo Sagaro*, Mihiretu Alemayehu \\ School of Public Health, College of Health Sciences and Medicine, Wolaita Sodo University, Wolaita Sodo, Ethiopia
}

Email address:

gamogetu48@gmail.com (G. G. Sagaro)

${ }^{*}$ Corresponding author

To cite this article:

Getu Gamo Sagaro, Mihiretu Alemayehu. Dietary Diversity and Associated Factors Among Infants and Young Children in Wolaita Zone, Southern Ethiopia. Science Journal of Clinical Medicine. Vol. 6, No. 4, 2017, pp. 53-59. doi: 10.11648/j.sjcm.20170604.12

Received: June 8, 2017; Accepted: June 21, 2017; Published: August 25, 2017

\begin{abstract}
Background: Increasing the variety of foods and food groups in the diet ensures that there is adequate intake of essential nutrients. Lack of dietary diversity especially for children 6-23 months is specifically critical because they require energy and nutrient-dense foods for both physical and mental growth and development. Encouraging children aged 6-23 months for appropriate complementary feeding practices reduces the incidence of stunting and leads to better health and growth outcome. A community based cross sectional study was conducted from May-June 2016, among children aged 6-23 months residing in rural districts of Wolaita Zone. Multi-stage sampling technique was applied to select 944 childmother/caregiver paired study population. Data was collected through a pre-tested and structured interviewer administered questionnaire consisting of demographic characteristics variables, household wealth indicators, and dietary assessment tool and entered using Epi-data manager and client entry version 1.4.4.0 and exported to SPSS Version 20 for analysis. Variables having $\mathrm{p}<0.25$ at bivariate analysis were fitted to multivariate analysis. Odds ratio, P-value and $95 \%$ CI were computed to show the association of variables. The proportion of children who consumed minimum acceptable dietary diversity was $43.2 \%$ (95\% CI: 40.0 - 46.6). The Diary and dairy products, meat, Vitamin A rich fruits and vegetables were less commonly consumed food groups. Older children (AOR $=2.49,95 \%$ CI: $1.71,3.64)$, maternal education of primary and secondary and above $(\mathrm{AOR}=$ $3.32,95 \% \mathrm{CI}: 2.01,5.22)$ and ( $\mathrm{AOR}=4.78,95 \% \mathrm{CI}: 2.55,8.95)$ were independent predictors of dietary diversity. Conclusion: Even though feeding practice of infants and young children is encouraging, plenty of children are still suffering from consuming inadequate dietary diversity. Hence, due attention has to be given to improve feeding practice of older children. Furthermore, improving parental education and economy result in proper child feeding practice.
\end{abstract}

Keywords: Dietary Diversity, Feeding Practice, Infants, Young Children, Wolaita

\section{Introduction}

Dietary diversity is the number of foods consumed across and within food groups over a reference period, usually 24 hours, 3 days or 7 days. Increasing the variety of foods and food groups in the diet ensures that there is adequate intake of essential nutrients. Lack of dietary diversity especially for children 6-59 months is specifically critical because they require energy and nutrient-dense foods for both physical and mental growth and development. Different evidence showed that in developed countries, dietary diversity is strongly associated with nutrient adequacy [1, 2]. Thestudy conducted in 11 countries using demographic health surveys regarding association between dietary diversity and child nutritional status in children 6-23 months showed that dietary diversity is independently associated with child nutritional status as a main effect or in association with other socio-economic factors [3, 4].

Malnutrition could occur as either under-nutrition, whereby there is inadequate intake of nutrients required by the body, or over-nutrition, where there is excessive supply. According to the Food and Agriculture Organization (FAO), approximately 868 million people were undernourished in 2012, with majority coming from developing countries [5]. Globally, in 2013 an approximately 6.3 million under five age children died and among those 2.9 million died in sub- 
Saharan Africa region [6]. In addition, about $60 \%$ of all child death is expected to occur in sub-Saharan Africa region and underlying causes of child death in the region including poverty, adverse climatic conditions, natural resource degradation, fragile and poorly accessible health care services and existence of socio-cultural misconceptions $[7,8]$.

Inappropriate complementary feeding practices are the most risk of under nutrition, illness, and mortality in both infants and young children less than 24 months of age, and more than two-thirds of children deaths related to malnutrition are associated with inappropriate feeding practices during the first 24 months of life [9, 10, and 11]. According to the Ethiopian demographic and Health Survey (EHDS, 2011), national rates of stunting, underweight and wasting among under 5 years children were $44.4,28.7$, and $9.7 \%$ respectively $[12,13]$. Encouraging children aged $6-23$ months for appropriate complementary feeding practices reduces the incidence of stunting and leads to better health and growth outcome $[14,15]$.

According to the Ethiopian Central Statistics Agency (CSA, 2011), the magnitude of appropriate complementary feeding practices among children aged 6-23 months is $4.8 \%$, which was very low [16]. According to the WHO, infant and young child feeding minimum dietary diversity proportion of children 6-23 months of age who received foods from four or more out of seven standard groups in the preceding days is as an imperative indicator [17]. However, in many low income countries including Ethiopia meeting minimum the dietary diversity standard has been a serious challenge. For instance, in Ethiopia only five percent of children met the requirement [18].

The current study was aimed at determining the prevalence of dietary diversity feeding practice and determinants among children aged 6-23 months residing in the rural districts of Wolaita Zone, Southern Ethiopia. Promoting dietary diversity is one of taking initiative measure that may be used to sensitize people to consume adequate energy and nutrients, because of this encourage good nutrition. The finding from this study will give possible interventions that can be used by government and different stakeholders to undertake malnutrition from childhood and to prevent the negative implications of malnutrition in adulthood. Also, this study provides evidence - based information for future studies on the same area.

\section{Methods and Materials}

\subsection{Study Design and Study Area}

A community based cross sectional study was conducted among children aged 6-23 months residing in rural districts of Wolaita Zone, Southern Ethiopia, from May-June 2016. Wolaita zone is one of the fourteen Zones found in the Southern Nations Nationalities and People
Region State (SNNPR) with 12 rural and 3 reform administrative towns. It is located at about $330 \mathrm{~km}$ south west of Addis Ababa, and $160 \mathrm{~km}$ from Hawassa, regional capital. The zone is located at $6^{\circ} 51^{\prime \prime}$ and $7^{\circ} 35^{\prime \prime}$ North Longitude; and $37^{\circ} 46^{\prime \prime}$ and $38^{\circ} 1^{\prime \prime}$ East Latitude and it is boarder by Gamo Gofa zone in the south, Dawuro Zone in the west, with Sidama Zone in the east, with Kambata \& Tambaro and Hadiya Zones in the north and Oromiya region in the northern east. Based on 2007 national population and housing census, the total population was 1.7 million from this $50.7 \%$ are male and $49.3 \%$ are female with annual population growth rate of $2.9 \%$ and child bearing age women 364,921 and making an estimated pregnancy 66,282 . Its projected population is 2.1 million in July 1, 2016 based on annual statistical abstract of CSA [19]. Majority (88.3\%) of the zone's people reside in rural districts whose major livelihood is agriculture. The major food crops cultivated in the zone are maize, sweet potato, Enset (false banana), teff (Eragrostistef), haricot bean, taro, sorghum, Irish potato, yam and cassava [20].

\subsection{Inclusion and Exclusion Criteria}

Mothers or care givers who have young children from 6 to 23 months living in the selected rural Kebeles (the smallest administrative cluster consisting of nearly 5000 population) for at least 6 months were included in the study and those who had mental illnesses or seriously ill during the interview were not considered in study.

\subsection{Sample Size Determination}

Sample size was calculated by using single population proportion formula with the following assumptions: prevalence of adequate minimum dietary diversity feeding practice of $23.3 \%$ in Southern Ethiopia [21], desired precision (d) $=4 \%$ and $95 \%$ confidence level. The calculated sample size was 429 and final sample size was calculated by taking design effect of 2 and $10 \%$ none response rate, which is 944 .

\subsection{Sampling Technique and Procedures}

Multi-stage sampling technique was applied to select child-mother/caregiver paired study population. Initially four districts were randomly selected from the 12 rural districts. As a result, Damot Gale, Boloso Bombe, Humbo and Sodo zuria districts were selected. Then three kebeles were randomly selected from respective districts, making the total number of kebeles included in the study to be 12 . Finally, study units were selected through systematic sampling technique from each selected Kebele by proportionally allocating the sample size with regard to the respective kebeles' population size.

\subsection{Data Collection Tool and Procedure}

Data was collected from mothers or care givers who have child aged 6 to 23 months from each household by 
direct interviewing. Pre - tested and structured questioner was used to collect data. First dietary diversity score tool was adapted from WHO infant and young child feeding practice guideline, which contains seven food groups for young child minimum dietary diversity from 6 to 23 months [22]. Minimum acceptable dietary diversity was defined as taking four or more food groups in the preceding day of the survey out of the seven standard food groups recommended by the WHO [23] without imposing a minimum intake restriction. Dietary diversity score (DDS) was computed by summing the number of unique food groups the child received in the preceding day of the survey. Data on dietary diversity was collected by allowing mothers freely to recall the type of food items feed their child within 24 hours. Then the data collector's records the child dietary diversity with the help of seven food items according to WHO guideline [24].

\subsection{Data Quality Control}

Questionnaire was prepared in English and translated to local language (Wolaita language). Interviewers were trained on the aim of the research, content of the questionnaire, and how to conduct interview for data collectors and supervisor to increase their performance in field activities prior to data collection and pre tested on $5 \%$ of mothers before actual data collection outside the selected rural kebeles; correction and modification was done based on pre-test. Two day training was given the Collected data was checked every day by supervisors and principal investigator for its completeness and consistency.

\subsection{Data Analysis and Management}

Data were entered using Epi-data manager and client entry version 1.4.4.0 and exported to SPSS Version 20 for analysis. The presence of multicollinearity also was checked and effort was made to incorporate different models to cross check. Frequencies and cross tabulation were calculated to describe the study population in relation to relevant variables. Binary logistic regression analysis was conducted to assess the association between dependent and independent variables. Finally Independent variables which show association in binary logistic regression analysis and those which have P-value less than 0.25 entered in to multivariate logistic regression model, to control confounding and identify significant factors associated with outcome variables. Finally significant factors were identified based on AOR include with 95\% confidence level and $\mathrm{P}$ value less than 0.05 .

\subsection{Operational Definition}

Minimum dietary diversity: Proportion of children 6-23 months of age who receive food from four or more food groups during the previous day considered as adequate and three and below is considered as inadequate (low). (1) grains, roots and tubers, (2) legumes and nuts, (3) dairy products (milk, yogurt, cheese), (4) flesh foods (meat, fish, poultry and liver/organ meats), (5) eggs, (6) vitaminA rich fruits and vegetables, (7) other fruits and vegetables [23].

\section{Ethical Consideration}

Ethical clearance was obtained from School of public health, College of Health Sciences and Medicine, Wolaita Sodo University. Local administrative bodies were also communicated and permission was obtained from the respective administrative bodies. Finally, informed consent was obtained from the mothers or caregivers.

\section{Result}

\section{Socio-demographic characteristics}

Among the total sample size $(n=944)$, nine hundred thirty nine mothers having children 6-23 months of age were interviewed, giving response rate of $99.5 \%$. The mean age of children was 14.9 months \pm 5.3 (SD) and among which $314(33.4 \%)$ were in the age group 6-11 months, $285(30.4 \%)$ were in $12-17$ months and rest 340 $(36.2 \%)$ found in 18-23 months. More than half 527 $(56.1 \%)$ of the children were female and seven in eight, 825 (87.9) mothers were housewife during data collection. Nearly one in three, 298 (31.7\%) and half, $473(50.4 \%)$ of the respondents had no education and visited ANC clinic 4 and above times, respectively (Table 1).

Dietary diversity (DD) assessment

The mean (SD) dietary diversity score (DDS) was 3.38 $( \pm 1.46)$. Overall, $406(43.2 \%)$ of children consumed at least four food groups, as recommended by WHO. The most commonly consumed food groups (92.4\%) were starchy staple foods including grains, roots and tubers. More than half (51.2\%) of children ate foods composed of legumes and pluses. Low feeding practice was observed on animal sources like eggs and flesh foods in which $32.2 \%$ and $1.6 \%$ of study participants ate, respectively. (Figure 1).

Factors Associated with children's dietary diversity score

After conducting multivariate analysis, children aged 12-23 months $(\mathrm{AOR}=2.49,95 \% \mathrm{CI}: 1.71,3.64)$, wealth index $(\mathrm{AOR}=0.47,95 \% \mathrm{CI}: 0.32,0.69)$ and $(\mathrm{AOR}=$ $0.47,95 \% \mathrm{CI}: 0.32,0.69)$ and mothers with primary and, secondary and above $(\mathrm{AOR}=3.32,95 \% \mathrm{CI}: 2.01,5.22)$ and $(\mathrm{AOR}=4.78,95 \% \mathrm{CI}: 2.55,8.95)$ were significantly associated with consuming minimum acceptable dietary diversity score (Table 2). 


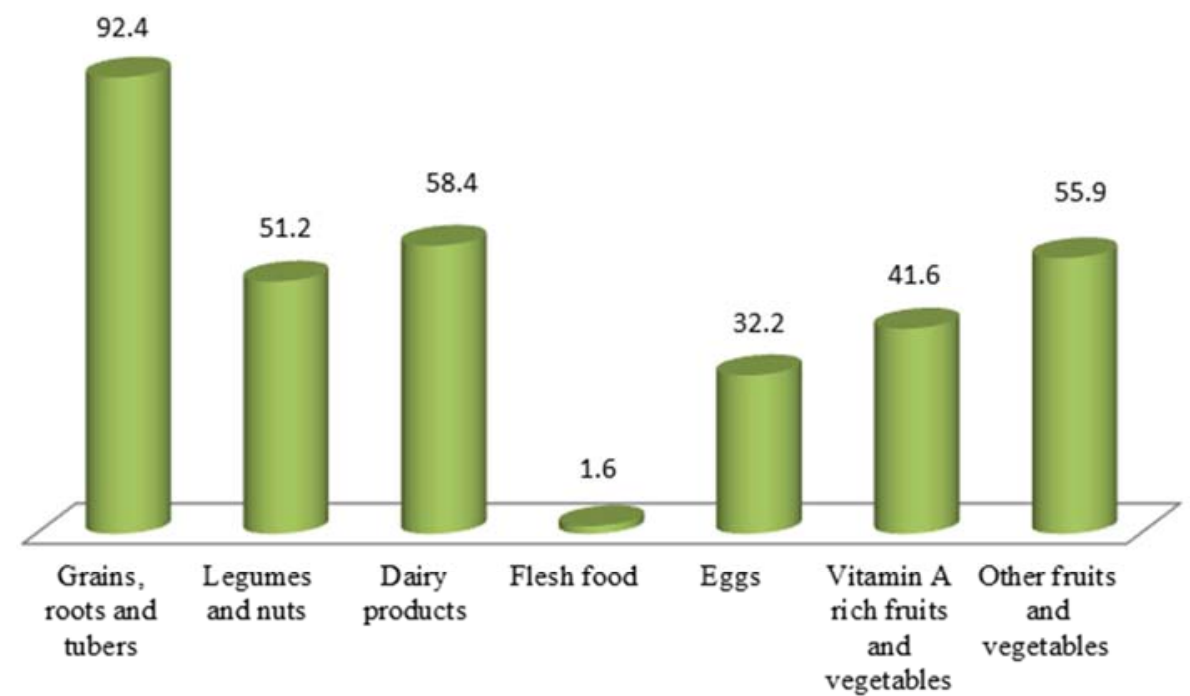

Figure 1. Types of food groups consumed by children aged 6-23 months, assessed by 24 hour recall.

Table 1. Socio-demographic characteristics of the respondents and study children in Wolaita Zone, Southern Ethiopia, 2017.

\begin{tabular}{|c|c|c|}
\hline \multirow{2}{*}{\begin{tabular}{|l} 
Variables \\
Mother age (year)
\end{tabular}} & \multirow{2}{*}{ Frequency } & \multirow{2}{*}{ Percentage } \\
\hline & & \\
\hline $15-24$ & 274 & 29.2 \\
\hline $25-34$ & 604 & 64.3 \\
\hline 35 and above & 61 & 6.5 \\
\hline \multicolumn{3}{|l|}{ Child age (months) } \\
\hline $6-11$ & 314 & 33.4 \\
\hline $12-17$ & 285 & 30.4 \\
\hline $18-23$ & 340 & 36.2 \\
\hline \multicolumn{3}{|l|}{ Sex of child } \\
\hline Male & 527 & 56.1 \\
\hline Female & 412 & 43.9 \\
\hline \multicolumn{3}{|l|}{ Mother's occupation } \\
\hline House wife & 825 & 87.9 \\
\hline Government employee & 39 & 4.2 \\
\hline Merchant & 32 & 3.4 \\
\hline Others & 43 & 4.6 \\
\hline \multicolumn{3}{|l|}{ Husband's Occupation } \\
\hline Farmer & 593 & 64 \\
\hline Government employee & 105 & 11.3 \\
\hline Merchant & 164 & 17.7 \\
\hline Daily laborer & 36 & 3.9 \\
\hline Others & 28 & 3.0 \\
\hline \multicolumn{3}{|l|}{ Mother's education } \\
\hline Secondary and above & 159 & 16.9 \\
\hline Primary & 482 & 51.3 \\
\hline No education & 298 & 31.7 \\
\hline \multicolumn{3}{|l|}{ Husband's education } \\
\hline Secondary and above & 248 & 26.4 \\
\hline Primary & 506 & 53.9 \\
\hline No education & 185 & 19.7 \\
\hline \multicolumn{3}{|l|}{ Family size } \\
\hline Below 5 & 287 & 30.6 \\
\hline $5-7$ & 437 & 46.5 \\
\hline 8 and above & 215 & 22.9 \\
\hline \multicolumn{3}{|l|}{ Marital status } \\
\hline In a union & 883 & 94 \\
\hline Not in a union & 56 & 6 \\
\hline \multicolumn{3}{|l|}{ Number of ANC visit } \\
\hline No visit & 82 & 8.7 \\
\hline Below 4 & 473 & 50.4 \\
\hline 4 and above & 384 & 40.9 \\
\hline
\end{tabular}


Table 2. Factors associated with minimum acceptable dietary diversity score of children aged 6-23 months in Wolaita Zone, Southern Ethiopia, 2017.

\begin{tabular}{|c|c|c|c|c|}
\hline \multirow{2}{*}{ Characteristics } & \multicolumn{2}{|l|}{ Dietary diversity } & \multirow{2}{*}{ COR $(95 \% C I)$} & \multirow{2}{*}{ AOR (95\%CI) } \\
\hline & In-adequate N (\%) & Adequate N (\%) & & \\
\hline \multicolumn{5}{|l|}{ Age of child (months) } \\
\hline $6-11$ & $203(64.6)$ & $111(35.4)$ & 1 & 1 \\
\hline $12-17$ & $170(59.6)$ & $115(40.4)$ & $1.24(0.89,1.72)$ & $1.32(0.89,1.94)$ \\
\hline $18-23$ & $160(47)$ & $180(53)$ & $2.06(1.50,2.82)$ & $2.49(1.71,3.64)$ \\
\hline \multicolumn{5}{|l|}{ Sex of child } \\
\hline Male & $302(57.3)$ & $225(42.7)$ & 1 & 1 \\
\hline Female & $231(56)$ & $181(44)$ & $1.05(0.81,1.36)$ & $0.93(0.68,1.27)$ \\
\hline \multicolumn{5}{|l|}{ Marital status } \\
\hline In a union & $490(55.5)$ & $393(44.5)$ & 1 & 1 \\
\hline Not in a union & $43(76.8)$ & $13(23.2)$ & $0.38(0.20,0.71)$ & $0.55(0.27,1.16)$ \\
\hline \multicolumn{5}{|l|}{ Mother education } \\
\hline Secondary and above & $60(37.7)$ & $99(52.3)$ & 1 & 1 \\
\hline Primary & $244(50.6)$ & $238(49.4)$ & $3.24(2.34,4.47)$ & $3.32(2.01,5.21)$ \\
\hline No education & $229(76.8)$ & $69(23.2)$ & $5.48(3.60,8.32)$ & $4.78(2.55,8.95)$ \\
\hline \multicolumn{5}{|l|}{ Husband education } \\
\hline Secondary and above & $108(43.5)$ & $140(56.5)$ & $3.23(2.15,4.84)$ & $1.19(0.65,2.22)$ \\
\hline Primary & $193(57.9)$ & $213(42.1)$ & $1.81(1.26,2.61)$ & $0.89(0.55,1.46)$ \\
\hline No education & $132(71.4)$ & $53(28.6)$ & 1 & 1 \\
\hline \multicolumn{5}{|l|}{ Mother occupation } \\
\hline Housewife & $470(57)$ & $355(43)$ & 1 & 1 \\
\hline Government employee & $14(35.9)$ & $25(64.1)$ & $2.37(1.21,4.62)$ & $0.93(0.39,2.21)$ \\
\hline Merchant & $17(53.1)$ & $15(46.9)$ & $1.17(0.58,2.37)$ & $0.58(0.24,1.41)$ \\
\hline Others & $32(74.4)$ & $11(25.6)$ & $0.46(0.23,0.92)$ & $0.16(0.07,0.39)$ \\
\hline \multicolumn{5}{|l|}{ Husband's Occupation } \\
\hline Farmer & $362(61)$ & $231(39)$ & 1 & 1 \\
\hline Government employee & $49(46.7)$ & $56(53.3)$ & $1.79(1.18,2.72)$ & $1.10(0.62,1.96)$ \\
\hline Merchant & $94(57.3)$ & $70(42.7)$ & $1.17(0.82,1.66)$ & $0.72(0.46,1.14)$ \\
\hline Daily laborer & $10(27.7)$ & $26(72.3)$ & $4.07(1.93,8.61)$ & $5.89(2.41,14.39)$ \\
\hline Others & $9(32)$ & $19(67.8)$ & $3.31(1.47,7.44)$ & $2.87(0.91,9.06)$ \\
\hline \multicolumn{5}{|l|}{ HFIAS } \\
\hline Food secure & $316(54)$ & $269(46)$ & $1.70(1.04,2.80)$ & $1.45(0.79,2.68)$ \\
\hline Mildly food insecure & $58(77.3)$ & $17(22.7)$ & $0.59(0.29,1.20)$ & $0.51(0.22,1.19)$ \\
\hline Moderately food insecure & $107(53.2)$ & $94(46.8)$ & $1.76(1.02,3.03)$ & $1.45(0.75,2.79)$ \\
\hline Severely food insecure & $52(66.7)$ & $26(33.3)$ & 1 & 1 \\
\hline \multicolumn{5}{|l|}{ Wealth Index } \\
\hline Low & $134(43.6)$ & $173(56.4)$ & 1 & 1 \\
\hline Middle & $177(63.9)$ & $100(36.1)$ & $0.44(0.32,0.61)$ & $0.47(0.32,0.69)$ \\
\hline High & $199(65.2)$ & $106(34.8)$ & $0.41(0.29,0.57)$ & $0.47(0.32,0.69)$ \\
\hline \multicolumn{5}{|l|}{ Family size } \\
\hline Below 5 & $142(49.5)$ & $145(50.5)$ & $1.72(1.20,2.47)$ & $1.28(0.82,2.02)$ \\
\hline $5-7$ & $256(58.6)$ & $181(41.4)$ & $1.193(0.85,1.67)$ & $1.11(0.74,1.66)$ \\
\hline 8 and above & $135(62.8)$ & $80(37.2)$ & 1 & 1 \\
\hline \multicolumn{5}{|l|}{ Number of ANC visit } \\
\hline No visit & $51(62.2)$ & $31(37.8)$ & 1 & 1 \\
\hline Below 4 & $270(57.1)$ & $203(42.9)$ & $1.24(0.76,2.00)$ & $0.86(0.48,1.55)$ \\
\hline 4 and above & $212(55.2)$ & $172(44.8)$ & $1.34(0.82,2.18)$ & $0.76(0.41,1.42)$ \\
\hline \multicolumn{5}{|l|}{ Delivery at health facility } \\
\hline Yes & $263(63.5)$ & $151(36.5)$ & $0.61(0.47,0.78)$ & $0.79(0.57,1.11)$ \\
\hline No & $270(51.4)$ & $255(48.6)$ & 1 & 1 \\
\hline
\end{tabular}

\section{Discussion}

About $43.2 \%$ of children consumed minimum acceptable number of food groups. This finding is high when compared with the result obtained from national prevalence of Ethiopia and the study conducted in North Ethiopia, which was $10.8 \%$ and $17.8 \%$, respectively $[25,26]$; but the present study finding is comparable with a study conducted in Bangladesh, in which $41.9 \%$ of study participants consumed at least four food groups [27]. The possible explanation for this variation is because of differences in methodology, study setting, study 
population dynamics, time of the study and related socioeconomic characteristics (factors). Low feeding practice is observed in diary and dairy products, Vitamin A rich fruits and vegetables. This is in line with study conducted in north Ethiopia [26].

As the child is growing up, his/her feeding practice is relatively compromised. i.e. children aged $18-23$ months were 2.49 times more likely to practice inadequate dietary diversity compared to children aged $6-11$ months $(\mathrm{AOR}=$ 2.49, 95\% CI: 1.71, 3.64). This indicates that greater attention is given to younger children during initiation of complementary feeding, whereas lesser attention is given to feed diverse food groups when they grow up.

Educational status of mothers/care givers is also found to be predictor of higher dietary diversity score. Accordingly, mothers with primary, and no formal education were 3.32 and 4.78 times more likely to practice feeding inadequate dietary diversity to their children than those educated above secondary level (AOR $=3.32,95 \% \mathrm{CI}: 2.01,5.21)$ and (AOR $=4.78,95 \% \mathrm{CI}: 2.55,8.95)$. This finding is in line with findings from other studies $[27,28,29,30]$. This implies that parental education plays an important role in meeting the minimum dietary diversity standards.

The present study also revealed the association between household economy and dietary diversity of children. Children born from middle and high wealth index household had 53\% less chance to feed inadequate dietary diversity compared with children from low wealth index household (AOR $=0.47,95 \%$ CI: $0.32,0.69)$ and (AOR $=0.47,95 \% \mathrm{CI}: 0.32,0.69)$, respectively. This may be due to the limited food purchasing power of people from less wealthier family [31].

Children whose father had daily laborer occupation 5.89 times more practice to inadequate dietary diversity when compared with children whose father farmer $(\mathrm{AOR}=5.89$, 95\% CI: 2.41, 14.39). This implies that Households where the fathers are engaged in agriculture-related occupations may have better complementary feeding practice when compared to households where the fathers are wage dependent. This finding was in line with the study conducted in Bangladesh [32]. Moreover, children whose mother or caregivers had others occupation like... were $84 \%$ less likely to practice inadequate dietary diversity when compared to children whose mother or caregiver was housewife (AOR = 0.16 ; $95 \% \mathrm{CI}: 0.07,0.39)$. This finding is similar to the reports from other researchers [33].

\section{Conclusion and Recommendation}

In general, $43.2 \%$ of infants and young children fed minimum acceptable dietary diversity within 24 hours preceding the survey, which is satisfactory when compared to other recent studies conducted in Ethiopia But still it needs improvements since plenty of infants and young children are in need of consuming diverse food for their growth and development. The factors that consistently affect dietary diversity were age of the child and level of maternal education. In addition, wealth index, occupation of mother and husband are factors which determine dietary diversity. Furthermore, improvements in education leading to higher level of parental education can result in practicing diverse food group feeding.

\section{Acknowledgements}

Wolaita Sodo University, respective zonal and district administrative offices, data clerk, data collectors and study participants deserve our special thank.

\section{Author's Contributions}

Mihiretu A: Conceived the study and participated in the design of the study; Mihiretu A and Getu G: Obtained ethical clearance and permission for the study, supervised data collection, performed statistical analysis interpreted the data and involved in drafting article. Both authors read and approved the final manuscript.

\section{References}

[1] Bernstein, M., Tucker, K., Ryan, N., O’Neil, E., Clements, K., Nelson, M., Evans, W. and Fiatarone S. (2002), "Higher Dietary Variety is Associated with Better Nutritional Status in Frail Elderly People," Journal of the American Dietetic Association 102: 1096-1104.

[2] Foote, J., Murphy, S., Wilkens, L., Basiotis, P. and Carlson, A. (2004), "Dietary Variety Increases the Probability of Nutrient Adequacy Among Adults," Journal of Nutrition 134: 1779-85.

[3] Arimond, M. and Ruel, M. T. (2004), "Dietary Diversity is Associated with Child Nutritional Status: Evidence from 11 Demographic and Health Surveys," Journal of Nutrition, 134: 2579-85.

[4] Ruel, M. (2003), "Operationalizing Dietary Diversity: A Review of Measurement Issues and Research Priorities," Journal of Nutrition 133: S3911-26.).

[5] Food and Agriculture Organization of the United Nations (2012), State of Food Insecurity in the World, Rome, Italy.

[6] Liu L, Oza S, Hogan D, Perin J, Rudan I, Lawn JE, et al. Global, regional, and national causes of child mortality in 200013 , with projections to inform post- 2015 priorities: an updated systematic analysis. Lancet. 2015; 385(9966): 430-40.

[7] Black RE, Victora CG, Walker SP, Bhutta ZA, Christian P, de Onis $\mathrm{M}$, et al. Maternal and child undernutrition and overweight in low-income and middle-income countries. Lancet. 2013; 382(9890): 427-51.

[8] Bain LE, Awah PK, Geraldine N, Kindong NP, Sigal Y, Bernard N, et al. Malnutrition in Sub-Saharan Africa: burden, causes and prospects. Pan Afr Med J. 2013; 15: 120.

[9] World Health Organization. Infant and young child feeding Model Chapter for textbooks for medical students and allied health professionals. Vol. II. Geneva Switzerland; 2009.

[10] Victora CG, Adair L, Fall C, Hallal PC, Martorell R, Richter $\mathrm{L}$, et al. Maternal and child undernutrition: consequences for adult health and human capital. Lancet. 2008; 371(9609): $340-57$. 
[11] Black RE, Allen LH, Bhutta ZA, Caulfield LE, de Onis M, Ezzati M, et al. Maternal and child undernutrition: global and regional exposures and health consequences. Lancet. 2008; 371(9608): 243-60.

[12] Central Statistical Agency. Ethiopia Demographic and Health Survey, D. a. Health, Editor 2011, ORC Macro Calverton, Maryland, USA: Addis Ababa, Ethiopia.

[13] Federal Ministry of Health, Family Health Department Ethiopia. National strategy for infant and young child feeding. Addis Ababa: Federal Ministry of Health, Family Health Department Ethiopia; 2004.

[14] Black RE, Victora CG, Walker SP, Bhutta ZA, et al, for the Maternal and Child. Undernutrition Group. Maternal and child undernutrition: maternal and child undernutrition and overweight in low-income and middle-income countries. Lancet. 2013; http://dx.doi.org/10.1016/S01406736(13)60937-X.

[15] UNICEF. Programming Guide for Infant and Young Child Feeding, Nutrition Section Programmes. New York: UNICEF; 2011.

[16] Central Statistical Agency. Ethiopia Demographic and Health Survey, D. a. Health, Editor 2011, ORC Macro Calverton, Maryland, USA: Addis Ababa, Ethiopia.

[17] World Health Organization. Indicators for assessing infant and young child feeding practices: Definitions. Geneva: WHO Press; 2008.

[18] Central Statistical Agency [Ethiopia], ICF International. Ethiopia demographic and health survey 2011. Addis Ababa, Claverton: Central Statistical Agency, ICF International; 2012.

[19] CSA Web Site wcge. Population Projection of Ethiopia. 2016.

[20] Prospects for integrating food and food production in Wolaita Sodo, Ethiopia: available at http://www.fao.org/wairdocs/ILRI/x5519B/x5519b19.htm accessed by Nov. 2016

[21] Gatahun EA, Abyu DM (2015) Dietary Diversity Feeding Practice and Determinants among Children Aged 6-23 Months in Kemba Woreda, Southern Ethiopia Implication for Public Health Intervention. J Nutr Food Sci S13: S13003. doi: 10.4172/2155-9600.1000S13003.

[22] World Health Organization. Indicators for assessing infant and young child feeding practices measurement: part II. Geneva, Switzerland: WHO; 2010.

[23] World Health Organization. Indicators for assessing infant and young child feeding practices: Part I. Geneva: WHO; 2008.
[24] Indicators for assessing infant and young child feeding practices: conclusions of a consensus meeting held 6-8 November 2007 in Washington D. C., USA.

[25] Federal Ministry of Health (2004) National strategy for Infant and Young Child Feeding (IYCF). Ethiopia: Federal Ministry of Health, Family Health Department.

[26] Mekbib E, Shumey A, Ferede S, Haile F (2014) Magnitude and factors associated with appropriate complementary feeding among mothers having children 6-23 months-of-age in Northern Ethiopia; a community based cross-sectional study: Journal of Food and Nutrition Sciences 2: 36-42.

[27] A. Patel, Y. Pusdekar, N. Badhoniya, J. Borkar, K. E. Agho, and M. J. Dibley, "Determinants of inappropriate complementary feeding practices in young children in India: secondary analysis of national family health survey 20052006," Maternal and Child Nutrition, vol. 8, no. 1, pp. 28-44, 2012.

[28] N. Joshi, K. E. Agho, M. J. Dibley, U. Senarath, and K. Tiwari, "Determinants of inappropriate complementary feeding practices in young children in Nepal: secondary data analysis of demographic and health survey 2006," Maternal and Child Nutrition, vol. 8, no. 1, pp. 45-59, 2012.

[29] A. Patel, Y. Pusdekar, N. Badhoniya, J. Borkar, K. E. Agho, and M. J. Dibley, "Determinants of inappropriate complementary feeding practices in young children in India: secondary analysis of national family health survey 20052006," Maternal and Child Nutrition, vol. 8, no. 1, pp. 28-44, 2012.

[30] S. Roy, A. Dasgupta, and B. Pal, "Feeding practices of children in an urban slum of Kolkata," Indian Journal of Community Medicine, vol. 34, no. 4, pp. 362-363, 2009.

[31] Melkam Aemro et al. Dietary Diversity and Meal Frequency Practices among Infant and Young Children Aged 6-23 Months in Ethiopia: A Secondary Analysis of Ethiopian Demographic and Health Survey 2011: Journal of Nutrition and Metabolism Volume 2013, Article ID 782931, 8 pages http://dx.doi.org/10.1155/2013/782931

[32] Saha K. K., Frongillo E. A., Alam D. S., Arifeen S. E., Persson L. Å. \& Rasmussen K. M. Appropriate infant feeding practices result in better growth of infants and young children in rural Bangladesh. American Journal of Clinical Nutrition 87, 1852-1859: 2008.

[33] World Health Organization. Complementary feeding. www.who.int/elena/titles/complementary_feeding/en/last updated March 2016 (Accessed April 20, 2016). 